\title{
Public Debt in a Descriptive Endogenous Growth Model
}

\author{
Alfred Greiner ${ }^{*}$

\begin{abstract}
In this paper we analyze a descriptive endogenous growth model with public debt. The government runs into debt, but, the primary surplus is a positive function of public debt such that the debt to GDP ratio becomes a meanreverting process. A balanced budget scenario yields a higher long-run growth rate than a scenario with permanent deficits if and only if the public deficit exceeds the net saving out of government bonds. Further, multiple balanced growth paths can arise and reducing the reaction of the primary surplus to public debt can generate endogenous cycles via a Hopf bifurcation.
\end{abstract} \\ Key Words: Public debt; Balanced budget; Endogenous growth; Stability. \\ JEL Classification Numbers: H63, O41
}

\section{INTRODUCTION}

Public debt constitutes a major threat for the development of quite a many economies in the European Union (EU). While it has not been a major point of concern until the mid 2000's, the financial crisis in 2007 lead to a drastic increase of the debt to GDP ratio in most countries in the EU. Some of those managed to reduce public debt since the early 2010's, but, some economies are still struggling with high debt ratios. Table 1 shows the evolution of the public debt to GDP ratios for the 19 euro area countries on average and for some selected economies as well.

One can see that on average the debt to GDP ratio declined in the 19 euro area economies until the mid 2000's but strongly increased in the years following the 2007 financial crisis and slightly declines since then. The evolution in individual countries, however, is quite different. While the debt ratio has declined in all economies until 2005, it increased in France, Germany and Portugal. The financial crisis in 2007 lead to a rise in each country. However, after the crisis had been overcome some economies achieved to reduce the debt ratio (Belgium, Germany, Ireland), whereas in

\footnotetext{
* Department of Business Administration and Economics, Bielefeld University, P.O. Box 100131, 33501 Bielefeld, Germany. e-mail: agreiner@uni-bielefeld.de.
}

173 
TABLE 1.

General government gross debt as a percentage of GDP.

\begin{tabular}{c|cccccc} 
& 1995 & 2000 & 2005 & 2010 & 2015 & 2018 \\
\hline euro area (19 countries) & 70.8 & 68.0 & 69.3 & 84.8 & 90.1 & 85.1 \\
Belgium & 130.5 & 108.8 & 94.6 & 99.7 & 106.4 & 102.0 \\
France & 55.8 & 58.2 & 67.4 & 85.3 & 95.6 & 98.4 \\
Germany & 54.8 & 58.8 & 66.9 & 81.8 & 71.6 & 60.9 \\
Ireland & 78.5 & 36.1 & 26.1 & 86 & 76.8 & 64.8 \\
Italy & 116.9 & 109.7 & 101.9 & 115.4 & 131.6 & 132.2 \\
Portugal & 58.3 & 50.3 & 67.4 & 96.2 & 128.8 & 121.5 \\
Spain & 61.7 & 58.0 & 42.3 & 60.1 & 99.3 & 97.1
\end{tabular}

Source: Eurostat, https://ec.europa.eu/eurostat/de/data/database (download on 19.10.2016 for 1995 and 2000 data and on 04.07.2019 for all other years.)

other economies it still rose further (France) or declined only to a minor degree (Italy, Portugal, Spain), showing that the evolution has been quite different.

As concerns the effect of high public debt to GDP ratios, the empirical literature does not yield a clear-cut picture. Sometimes, it is argued that the effect of public debt on economic growth is hump-shaped: First, higher public debt to GDP ratios go along with higher economic growth, but, once a certain threshold is reached public debt is negatively correlated with economic growth (see e.g. Checherita-Westphal and Rother, 2012). Other empirical studies do not find that nonlinear effect and state that public debt and economic growth are only negatively correlated (see e.g. Eberhardt and Presbitero, 2015). Other studies find a statistically negative effect for developed countries (see Fincke and Greiner, 2016), whereas the relation between debt and economic growth is satistically positive for fast growing developing economies (see Fincke and Greiner, 2015). Summarizing the empirical studies, it seems that for developed economies the relation between public debt and economic growth is negative, but, the effect is not too high. In particular, the effects differ between countries. The fact that financial debt, public and private, has posed a problem for centuries that may trigger severe crisis has been demonstrated in Reinhart and Rogoff (2014). That holds because there is not a so-called soft budget constraint, but, the budget constraint of public and private economic agents is binding, as shown by Luo (2014). A survey of empirical studies dealing with the question how public debt affects the evolution of economies can be found in Arcabic et al. (2018), for example.

Theoretical endogenous growth models allowing for public debt often find that a higher public debt to GDP ratio goes along with a lower longrun balanced growth rate. The reason for that outcome is that the gov- 
ernment must stick to the inter-temporal government budget constraint. Hence, when the debt to GDP ratio rises public spending relative to GDP must decline for a given tax rate. When public spending is productive this shows negative growth effects. But, even in the case of unproductive public spending a higher debt ratio can lead to lower growth because a higher debt ratio implies that the government claims a higher share of aggregate saving, implying that the return to investment is reduced such that saving and labour supply decline (see Greiner and Fincke, 2015). However, when inflexible labour markets are taken into account, things can change. Then, public debt is neutral and does not affect the allocation of resources so that a higher debt to GDP ratio can go along with higher growth and lower unemployment if public spending is productive (see again Greiner and Fincke, 2015). As regards the dynamics, it has been shown in Greiner (2014) that an endogenous growth model with optimizing agents can generate endogenous cycles, depending on how strong the reaction of the government to past public debt is. In a similar model, Kamuguchi and Tamai (2011) demonstrate that government debt and economic growth are sustainable only if the long-run ratio of debt to GDP is within a certain range and they show that there exists an upper bound with respect to the debt to GDP ratio that is compatible with sustained growth. A similar research question is addressed by Kondo (2017) who calculates the public debt to GDP ratio that is compatible with a balanced growth path and, then, derives the set of consumption and income tax rates that guarantees a sustainable debt policy.

Besides the question how the deficit policy of the government affects the allocation of resources, its effect on the dynamics of the model economy often stands at the center of the analysis. For example, Futagami et al. (2008) study an endogenous growth model with productive public spending and public debt and assume that government debt must converge to a certain exogenously given debt ratio asymptotically. They demonstrate that there exist two balanced growth paths to which the economy can converge in the long-run, with one being saddle point stable and the other being saddle point stable or asymptotically stable. Morimoto et al. (2017) analyze a small open economy version of that model and can demonstrate that indeterminate equilibrium paths can be avoided by sufficiently low debt to GDP ratios and they show that endogenous limit cycles can arise in their model.

In this paper, we intend to contribute to the research on the effects of public debt as regards economic growth and stability of an economy. To do so, we consider a simple descriptive endogenous growth model and we analyze the impact of different debt policies. Thus, we study a balanced budget scenario and compare it to the scenario with permanent deficits. As concerns the source of permanent growth, we assume that ongoing growth 
is the result of learning-by-doing that generates sustained growth. We are interested in the effects of public debt policies with respect to economic growth and in their effects on the dynamics of the model.

In the rest of the paper we proceed as follows. In the next section we present the structure of our growth model. Section 3 analyzes growth effects along the balanced growth path of the different debt policies and section 4 studies the dynamics of the model economy. Section 5, finally, concludes the paper and compares the outcome of this model to those of other endogenous growth models with public debt.

\section{THE STRUCTURE OF THE GROWTH MODEL}

We consider a closed economy that consists of a household sector which receives labour income and income from its saving, a productive sector and the government. The household sector saves a given part of its income. Saving is used for investment in the aggregate stock of physical capital, $K$, and to finance the deficit of the government. The equation describing the use of saving is given by

$$
\dot{K}+\delta_{k} K+\dot{B}=s Y(1-\tau)+s(1-\tau) i_{b} B
$$

with $B$ denoting public debt, $\delta_{k}$ the depreciation rate of capital, $s$ the exogenous savings rate, $Y$ output, i.e. GDP, $i_{b}$ the interest rate on government bonds, $\tau$ the tax rate on the income of the household and the dot over a variable gives the derivative with respect to time. Government debt can be negative implying that the government is a creditor that lends to the private sector. It should be pointed out that, in this case, the private sector can deduce interest payments from its gross income so that its net income after taxes is given by $(1-\tau)\left(Y+i_{b} B\right)$, with $B$ being negative.

The government levies an income tax and can run deficits to finance unproductive public spending, $G$. The period budget constraint is written as

$$
\dot{B}=i_{b} B+G-\tau Y-\tau i_{b} B
$$

Further, the government sets the primary surplus, $S_{p}$, such that it is a positive function of public debt. The economic rationale behind that assumption is that the debt to GDP ratio becomes a mean-reverting process when the primary surplus rises as public debt increases so that the debt to GDP ratio remains bounded (see Bohn, 1998) if the reaction is sufficiently strong. Formally, this relation is described by

$$
S_{p}=\psi B+\phi Y
$$


with $\psi \in \mathbb{R}_{++}$giving the reaction of the primary surplus to higher public debt. The parameter $\psi$ can vary over time, but, must be positive on average. Thus, $\psi$ can be interpreted as the average reaction coefficient. It should be pointed out that, in case of a negative government debt, this rule guarantees that the outstanding debt of the private sector relative to GDP does not explode. The parameter $\phi \in \mathbb{R}$ may be positive or negative and shows how the government sets the primary surplus as GDP grows. That parameter reflects the discretionary scope of the government. Positive values of $\phi$ can be seen to characterize a stability-oriented government that raises the primary surplus as GDP increases, while a negative value of that parameter implies that a higher GDP leads to a smaller primary surplus.

The aggregate production function in the economy is written as

$$
Y=K^{\alpha}(A L)^{1-\alpha}=K^{\alpha} A^{1-\alpha},
$$

with $L$ the constant aggregate labour input that is set equal to one, $L=1$, and $A$ the stock of knowledge that reflects experience that is formed as a by-product of production. Thus, we intend to formalize the process of learning-by-doing (see Arrow, 1962), where knowledge is a function of past production. Formally, that relation is described by

$$
A=\rho \int_{-\infty}^{t} e^{\delta_{a}(\mu-t)} Y(\mu) d \mu \leftrightarrow \dot{A}=\rho Y-\delta_{a} A .
$$

As regards the factor markets we assume competitive markets such that the factor prices equal their marginal products. Hence, the interest rate, $i$, equals the marginal product of capital,

$$
i=\alpha K^{\alpha-1} A^{1-\alpha} .
$$

Since the physical capital stock is subject to depreciation, a no-arbitrage condition implies that the return to government bonds is determined by $i_{b}=i-\delta_{k}$.

Combining the equations (1) and (2), using the primary surplus rule (3) and the equation describing the evolution of the stock of knowledge (5), the economy is completely described by the following system of differential equations

$$
\begin{aligned}
\dot{K} & =s Y(1-\tau)+s(1-\tau)\left(i-\delta_{k}\right) B-\delta_{k} K-\left(i-\delta_{k}\right) B+\phi Y+\psi B \\
K(0) & =K_{0} \\
\dot{B} & =\left(i-\delta_{k}\right) B-\phi Y-\psi B, B(0)=B_{0} \\
\dot{A} & =\rho Y-\delta_{a} A, A(0)=A_{0}
\end{aligned}
$$




\section{ANALYSIS OF THE MODEL}

When analyzing the model we are interested in situations with ongoing growth. First, we study implications of different debt policies as regards growth along the balanced growth path and, then, we analyze transition dynamics.

\subsection{The balanced growth path}

To start with we define the notion of a balanced growth path.

Definition 3.1. A balanced growth path (BGP) is a path such that physical capital and knowledge grow at the same strictly positive constant growth rate, i.e. $\dot{K} / K=\dot{A} / A=\gamma, \gamma>0, \gamma=$ constant, and either

(i) $\dot{B} / B=\gamma$ or

(ii) $\dot{B}=0$.

This definition shows that physical capital and knowledge and, thus, output grow at a constant and strictly positive rate over time on a BGP. Public debt may be either constant, when the government budget is balanced, or it can grow at the same rate as capital and output. In the latter case, the government runs permanent deficits or permanent surpluses if public debt is negative, i.e. if the government is a creditor.

To further analyze our model we define the new variables $k \equiv K / A$ and $b \equiv B / A$. Differentiating those variables with respect to time yields

$$
\begin{aligned}
\dot{k}= & k\left(s(1-\tau) k^{\alpha-1}-(1-s(1-\tau))\left(\alpha k^{\alpha-1}-\delta_{k}\right)(b / k)-\delta_{k}+\right. \\
& \left.\phi k^{\alpha-1}+\psi(b / k)-\rho k^{\alpha}+\delta_{a}\right), k(0)=k_{0} \\
\dot{b}= & b\left(\alpha k^{\alpha-1}-\delta_{k}-\phi\left(k^{\alpha} / b\right)-\psi-\rho k^{\alpha}+\delta_{a}\right), b(0)=b_{0}
\end{aligned}
$$

where we used (7)-(9) and the marginal productivity rule (6). A rest point of (10)-(11) gives a BGP.

Next, we study the balanced growth path for the case of a balanced government budget. A balanced government budget is obtained by setting $\phi=0$ and $\psi=i_{b}$ which can be seen from (8). Prposition 1 shows that there exists a unique stable BGP for this case.

Proposition 1. Assume that the government runs a balanced budget. Then, there exists a unique asymptotically stable balanced growth path for a sufficiently small depreciation of knowledge.

Proof. Setting $\phi=0$ and $\psi=i_{b}$ shows that $\dot{k}$ is independent of $b$ and that there exists a unique intersection with the horizontal axis. Further, the derivatives of $\dot{k}$ and $\dot{b}$ with respect to $k$ and $b$, respectively, are both negative showing that the system is asymptotically stable. 
Proposition 1 demonstrates that the economy converges to a unique balanced growth path in the long-run when the government runs a balanced budget. Hence, a balanced government budget stabilizes the economy. The condition that the depreciation rate of knowledge capital is small is not strict. From a technical point of view it is necessary because a rest point of $\dot{k}$ may go along with negative long-run growth unless $\delta_{a}$ is small. For the case of permanent deficits, the analysis does not yield a similarly unequivocal outcome.

To analyze our model for the case of permanent deficits we first consider the $\dot{b}=0$ isocline. The following lemma gives properties of that curve.

LEMMA 1. The $\dot{b}=0$ isocline has the following properties: $b \rightarrow 0$ for $k \rightarrow 0, b \rightarrow-\phi / \rho$ for $b \rightarrow \infty$ and there exists a pole for $k=k_{p}$, with $k_{p}$ implicitly defined by $0=\alpha k^{\alpha-1}-\rho k^{\alpha}+\delta_{a}-\delta_{k}-\psi$. For $k<k_{p}$ public debt is negative (positive) for $\phi<(>) 0$. For $k>k_{p}$ public debt is negative (positive) for $\phi>(<) 0$.

Proof. Solving $\dot{b}=0$ gives $b=\phi k^{\alpha} /\left(\alpha k^{\alpha-1}-\rho k^{\alpha}+\delta_{a}-\delta_{k}-\psi\right)$. Letting $k \rightarrow 0$ and $k \rightarrow \infty$ and noting that to the left (right) of $k_{p}$ the denominator of $b$ along the $\dot{b}=0$ isocline is positive (negative) gives the results in the lemma.

Lemma 1 shows that the $\dot{b}=0$ isocline has a discontinuity at $k=k_{p}$ and the position of the BGP value of $k$ relative to that threshold determines whether the government is a debtor or a creditor in the long-run, together with the sign of $\phi$ that determines how the primary surplus changes as GDP rises.

In the following, we will focus on situations where the debt to knowledge ratio remains bounded. The condition for a bounded debt ratio is given in the following lemma.

Lemma 2. Assume that the interest rate and the growth rate of knowledge are constant. Then, the debt to knowledge ratio remains bounded if and only if $\psi>i_{b}-\gamma_{A}$ holds, with $\gamma_{A}=\dot{A} / A$.

Proof. The debt to knowledge ratio evolves according to the differential equation $\dot{b}=b\left(i_{b}-\psi-\gamma_{A}\right)-\phi k^{\alpha}$. Solving that differential equation immediately gives the outcome of the lemma.

Lemma 2 shows that the debt to knowledge ratio ${ }^{1}$ remains bounded only if the reaction of the primary surplus relative to GDP as the debt ratio rises,

\footnotetext{
${ }^{1}$ Equivalenty, this holds for the debt to GDP ratio.
} 
$\psi$, exceeds the difference between the interest rate on public debt and the growth rate of knowledge. The economic rationale behind that result is obvious. As long as the interest rate on public debt, $i_{b}$, is positive public debt is an explosive process. The government counter-runs this explosive process by running primary deficits. Hence, in order to avoid that the debt ratio becomes unbounded the government must set the primary surplus such that the destabilizing effect of an additional unit of the debt relative to knowledge, $i_{b}-\gamma_{A}$, is dominated by the rise in the primary surplus relative to GDP, $\psi$.

Given lemma 1 and lemma 2 we can now state a result showing how the primary deficit policy of the government determines the debt ratio in the economy along the BGP. This is the contents of proposition 1.

Theorem 1. Assume that the debt to knowledge ratio remains bounded. Then, public debt on the BGP is positive (negative) if the government reduces (raises) the primary surplus as GDP increases.

Proof. Solving $\dot{b} / b=0$ gives $b^{\star}=-\phi\left(k^{\star}\right)^{\alpha} /\left(\psi-i_{b}+\gamma\right)$, with the * denoting variables on the BGP. The debt to knowledge ratio remains bounded if and only if $\psi>i_{b}+\gamma$ holds giving the result in the proposition.

Proposition 1 shows that the discretionary deficit policy of the government is decisive as concerns its net fiscal position on the BGP. When the government raises the level of the primary surplus as GDP grows, public debt will be negative in the long-run, i.e. the government will be a creditor. On the other hand, when the primary surplus declines with a rising GDP, the government will be a debtor in the long-run. The latter case is the more realisitic and in the following we will focus on such a stituation.

Next, we compare growth effects of the balanced budget scenario to the scenario where the government runs permanent deficits for the economy on the BGP. The result is given in proposition 2.

THEOREM 2. The balanced budget scenario goes along with a higher balanced growth rate compared to the scenario with permanent public deficits if and only if the public deficit exceeds the net saving out of interest payments on government bonds.

Proof. The balanced growth rate is given by $\gamma=\dot{A} / A=\rho\left(k^{\star}\right)^{\alpha}-\delta_{a}$ showing that the balanced growth rate is the higher, the higher is $k^{\star}$ for given values of $\rho, \alpha$ and $\delta_{a}$. In the case of a balanced government budget, 
$k^{\star}$ is determined by

$$
\frac{\dot{K}}{K}=\frac{\dot{A}}{A} \leftrightarrow s(1-\tau) k^{\alpha-1}-\delta_{k}=\rho k^{\alpha}-\delta_{a}
$$

The $\dot{K} / K$ curve is monotonically declining in $k$ and the $\dot{A} / A$ curve is monotonically rising in $k$. In the case of public deficits, the $\dot{A} / A$ curve does not change while the $\dot{K} / K$ curve is now given by,

$$
\frac{\dot{K}}{K}=s(1-\tau) k^{\alpha-1}-\delta_{k}-C_{1}, \quad \text { with } \quad C_{1}=\left(\frac{b}{k}\right)\left(\frac{\dot{B}}{B}-s(1-\tau) i_{b}\right)
$$

For $C_{1}>(<) 0$ the $\dot{K} / K$ curve with public deficits is everywhere below (above) the $\dot{K} / K$ curve with a balanced budget, yielding a lower (higher) $k^{\star}$ and, consequently, a lower (higher) balanced growth rate.

Proposition 2 shows that a scenario with a balanced government debt performs better than the deficit scenario, in terms of long-run growth, if the public deficit exceeds the net saving out of government debt. The reason behind that result is as follows. On the one hand, public deficits imply that the government claims a certain part of aggregate saving for its purpose which reduces aggregate saving and investment leading to lower long-run growth. On the other hand, if the government pays interest on its outstanding debt this adds to the income of the household sector. A certain part of this income is saved and if this component exceeds the public deficit, total saving in the economy is higher, compared to the situation with a balanced government budget, such that economic growth rises.

The focus in our analysis is on the situation with the government being a debtor, rather than a creditor, since this is the more realistic case. Nevertheless, for sake of completeness we briefly discuss the situation with the government being a creditor, too. If the government is a creditor, implying that the private sector is a debtor, a balanced government budget yields a higher long-run growth rate than a scenario where the government is a creditor if the surplus of the government falls short of the saving out of net interest payments of the private sector on its outststanding debt to the government, in absolute terms. In particular, this is to be expected in the case of a very high indebteness of the private sector.

In the next subsection, we study transition dynamics of our model and we illustrate some of the analytical outcomes of this subsection.

\subsection{Transition Dynamics}

Proposition 1 already shows that the economy with a balanced government debt is asymptotically stable. Hence, we do not treat the balanced 
TABLE 2.

The balanced growth rate, $\gamma$, the debt to knowledge ratio, $b^{\star}$, and stability for the balanced budget scenario, with permanent deficits $(\phi=-0.03)$ and with permanent surpluses $(\phi=0.03)$ for $\psi=0.1$.

\begin{tabular}{c|ccc} 
& balanced budget & permanent deficits & permanent surpluses \\
\hline growth rate & $\gamma=1.73 \%$ & $\gamma=1.67 \%$ & $\gamma_{1}=0.92 \%, \quad \gamma_{2}=1.8 \%$ \\
debt ratio & $b^{\star}=0$ & $b^{\star}=1.118$ & $b_{1}^{\star}=-11.458, \quad b_{2}^{\star}=-1.004$ \\
stability & asymp. stable & stable focus & saddle point, stable node
\end{tabular}

budget scenario in detail and we focus our considerations on the case of permanent deficits. For the economy with permanent deficits, however, the analysis of the analytical model does not yield unequivocal results. The only outcome that can be stated is that the reaction coefficient $\psi$ must be sufficiently high such that the economy does not become explosive what has been stated in lemma 2 .

In the following, we resort to a numerical example in order to gain further insight into the dynamics of our model. To do so we use the following parameter values. The savings rate is set to $s=0.17$, the elasticity of output with respect to physical capital is 30 percent, $\alpha=0.3$, and the tax rate is set to $\tau=0.15$. The deprecication rate of physical capital is $\delta_{k}=0.035$ and knowledge depreciates at the rate $\delta_{a}=0.06$. The parameter $\rho$ reflecting the learning-by-doing effect is set to $\rho=0.05$. Further, in the case of an unbalanced government budget, the reaction coefficient giving the response of the primary surplus to variations in debt is set to $\psi=0.1$ The parameter $\phi$ is set to $\phi=-0.03$ and to $\phi=0.03$, respectively. Table 2 reports the result of the model with these parameter values.

One realizes that the balanced budget scenario yields a higher balanced growth rate than the scenario with permanent deficits, with $\phi=-0.03$. The reason for that outcome is that in the case of public deficits the government requires a certain fraction of aggregate saving that cannot be used for investment, thus, lowering long-run growth. This deficit exceeds the additional saving out of the interest income payed by the government to the private sector. It should be noted that the public debt to knowledge ratio $b^{\star}=1.118$ implies a debt to GDP ratio of $73 \%$.

In the case of permanent surpluses with $\phi=0.03$, there exist two BGPs. The first with the very high negative government debt is characterized by a low long-run growth rate that falls short of that of the scenario with a balanced government budget. In that case, the high debt of the private sector implies high feedback effects in the form of high debt services of the private sector such that aggregate saving is smaller than in the situation with a balanced government budget. It must be noted that this BGP is nongeneric. This holds because it is saddle point stable and the savings rate 
TABLE 3.

The balanced growth rate, $\gamma$, the debt to knowledge ratio, $b^{\star}$, and stability with permanent deficits $(\phi=-0.03)$ and with permanent surpluses $(\phi=0.03)$ for $\psi=0.076$.

\begin{tabular}{c|cc} 
& permanent deficits & permanent surpluses \\
\hline growth rate & $\gamma_{1}=1.31 \%, \quad \gamma_{2}=1.58 \%$ & $\gamma=1.87 \%$ \\
debt ratio & $b_{1}^{\star}=180.855, \quad b_{2}^{\star}=3.408$ & $b^{\star}=-1.846$ \\
stability & saddle point, stable focus & stable node
\end{tabular}

is exogenously given, such that it cannot be reached unless the economy starts on the BGP at $t=0$. The second BGP is a stable node and yields a higher growth rate than the balanced budget scenario. In that case the lending of the government to the private sector raises the income of the private sector and, thus, aggregate saving and investment so that the longrun growth rate is higher than in the balanced budget scenario. It should be noted that a (negative) public debt to knowledge ratio of $b_{1}^{\star}=-11.458$ and $b_{2}^{\star}=-1.004$ go along with a (negative) public debt to GDP ratio of about $830 \%$ and of $64 \%$, respectively.

It should also be pointed that, in the case of the permanent deficits in table 2, there exists a second rest point of (10)-(11). However, that rest point implies $\psi<i_{b}-\gamma$ such that the debt to knowledge ratio $B / A$ does not remain bounded giving rise to a contradiction. Therefore, this rest point does not make sense from an economic point of view. However, for smaller values of the reaction coefficient $\psi$ there exist 2 reasonable BGPs for the model with a positive government debt, too. This is demonstrated in table 3 , where we set $\psi=0.076$.

Table 3 demonstrates that there now exist 2 BGPs for the model with the government being a debtor. The first one is a saddle point while the second is again a stable focus and both are associated with a lower balanced growth rate than the balanced budget scenario. The scenario with permanent surpluses is characterized by a unique BGP that is a stable node and that yields again a higher balanced growth rate than the scenario with a balanced government budget. It should be noted that there exists a second rest point of (10)-(11) with permanent surpluses. However, that rest point implies $\psi<i_{b}-\gamma$ such that the debt to knowledge ratio $B / A$ does not remain bounded on the BGP so that it does not make sense from an economic point of view.

From table 2 and table 3 one can see that the scenario with permanent deficits is a stable focus, i.e. the eigenvalues of the Jacobian are complex conjugate with a negative real part. If the reaction coefficient $\psi$, determining how strong the government raises the primary surplus as public debt rises, is reduced the real part of the eigenvalues declines and for 
$\psi=\psi_{\text {crit }}=0.074526$ there exist two purely imaginary eigenvalues. Further reducing $\psi$ the real parts become positive implying that the system is unstable then. This suggests that a Hopf bifurcation occurs at $\psi=\psi_{\text {crit }}$ that gives rise to stable limit cycle which is confirmed by a bifurcation analysis. ${ }^{2}$ The Lyapunov coefficient is computed as $l_{1}=-2.98 \cdot 10^{-3}<0$ demonstrating that the limit cycle is an attractor.

Figure 1 shows the outcome of the bifurcation analysis with the bifurcation parameter $\psi$ shown on the vertical axis. The label $H$ denotes the point where the Hopf bifurcation arises, at $\left(b^{\star}=4.1386, k^{\star}=3.974, \psi=0.0745\right)$, and $L P$ stands for the limit point that occurs at $\left(b^{\star}=8.7437, k^{\star}=\right.$ $3.8287, \psi=0.0726)$. There exist 2 BGPs for values of $\psi$ higher than $\psi=0.0726$ that determines the limit point $L P$ and there is no BGP for values lower than that value.

FIG. 1. Bifurcation diagram with $\psi$ as the bifurcation parameter and $\phi=-0.03$, with $H$ denoting the Hopf bifurcation and $L P$ the limit point.

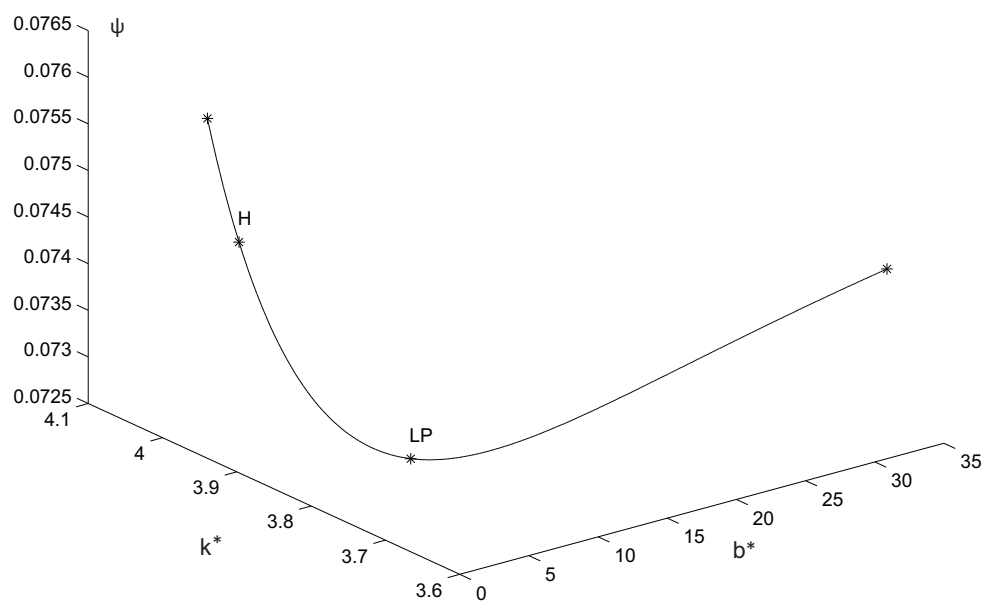

Figure 2 shows the limit cycle with the parameter $\psi$ set to a slightly smaller value than the critical value. It should be noted that the limit cycle is generic since it occurs for an interval of $\psi$ with a strictly positive measure.

\section{CONCLUSION}

In this paper we have analyzed the effects of public debt in a simple descriptive endogenous growth model with an exogenously determined sav-

\footnotetext{
${ }^{2}$ The bifuraction analysis and the limit cycle have been computed with the software CL_MATCONT, see Dhooge et al. (2003).
} 
FIG. 2. Limit cycle in the $(b-k-\psi)$ plane with $\psi$ slightly below the critical value $\psi_{\text {crit }}$.

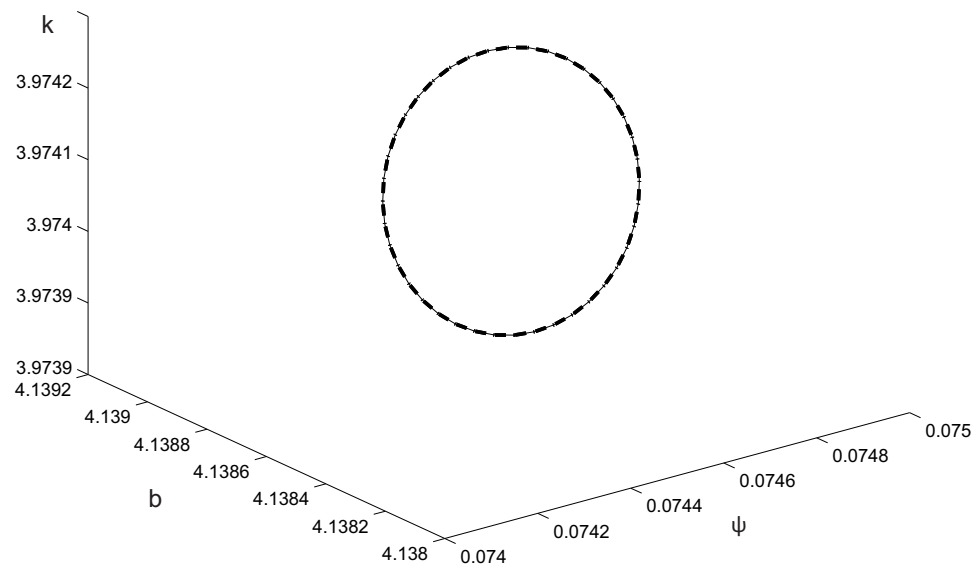

ings rate, where ongoing growth is the result of learning-by-doing effects. Assuming that the government raises the primary surplus as public debt rises such that the debt to GDP ratio becomes a mean-reverting process, we could derive the following results.

Comparing the balanced budget scenario to a scenario with permanent deficits, it turned out that a balanced budget scenario leads to higher longrun growth if the public deficit exceeds the saving out of net interest payments on public debt. The economic rationale behind that result is that public deficits reduce aggregate saving and investment whereas a certain part of the interest payments are saved that raises aggregate saving. The same ambiguous result is obtained when the government is a creditor that lends to the private sector. It should be pointed out that this result is contrary to what has been derived for the model with an endogenously determined savings rate, where a higher public debt always reduces long-run growth (see Greiner and Fincke, 2015), unless the labour market is rigid.

Analyzing transition dynamics we found that this simple model can give rise to a relatively complex outcome, in contrast to the model with an optimizing household sector where the situation with an unbalanced government budget is either stable or unstable, depending on the size of the reaction of the primary surplus to public debt (see again Greiner and Fincke, 2015). Resorting to a numerical example, it turned out that the model can give rise to two balanced growth paths, with one being stable the other unstable. Further, it was shown that the reaction of the primary surplus to higher public debt is decisive as regards stability of the model. Hence, for a high reaction coefficient the model is stable while it becomes unstable 
when this coefficient is reduced. In addition, we could show that for certain values of that parameter a stable limit cycle can occur implying that the long-run growth rate is not constant, but, characterized by persistent oscillations.

Even if this model is rather a stylized and simple one, it adds to our understanding of the effects of public debt, in particular if the results are seen in the context of the outcome of other models of this line of research. As concerns future research, one could think of modelling the government sector in a more complex way, for example by allowing for productive public spending. It would also be interesting to see how the integration of a monetary sector, where a central bank controls the money supply, affects the outcome. Finally, giving up the assumption of a closed economy and taking into consideration that most real-world economies are involved in international trade could lead to valuable further insight.

\section{REFERENCES}

Arcabic, Vladimir, Josip Tica, Junsoo Lee, and Robert J. Sonora, 2018. Public debt and economic growth conundrum: nonlinearity and inter-temporal relationship. Studies in Nonlinear Dynamics and Econometrics 22, DOI: https://doi.org/10.1515/snde2016-0086

Arrow, Kenneth J., 1962. The economic implications of learning by doing. Review of Economic Studies 29, 155-173.

Bohn, Henning, 1998. The behaviour of U.S. public debt and deficits. Quarterly Journal of Economics 113, 949-963.

Checherita-Westphal, Christina and Philip Rother, 2012. The impact of high government debt on economic growth and its channels: An empirical investigation for the euro Area. European Economic Review 56, 1392-1405.

Dhooge, Annick, Willy Govaerts, Yuri A. Kuznetsov, W. Maestrom, and A. M. Riet, 2003. CL_MATCONT: A continuation toolbox in Matlab. Ghent University.

Eberhardt, Markus and Andrea F. Presbitero, 2015. Public debt and growth: Heterogeneity and non-linearity. Journal of International Economics 97, 45-58.

Fincke, Bettina and Alfred Greiner, 2015. Public debt and economic growth in emerging market economies. South African Journal of Economics 83, 357-370.

Fincke, Bettina and Alfred Greiner, 2016. On the relation between public debt and economic growth: An empirical investigation. Economics and Business Letters 4, 137-150.

Futagami, Koichi, Tatsuro Iwaisako, and Ryoji Ohdoi, 2008. Debt policy rule, productive government spending, and multiple growth paths. Macroeconomic Dynamics 12, 445-462.

Greiner, Alfred, 2014. Public debt and the dynamics of economic growth. Annals of Economics and Finance 15, 185-204.

Greiner, Alfred and Bettina Fincke, 2015. Public Debt, Sustainability and Economic Growth. Theory and Empirics. Springer Verlag, Cham.

Kamiguchi, Akira and Toshiki Tamai, 2012. Are fiscal sustainability and stable balanced growth simultaneously attainable? Metroeconomica 63, 443-457. 
Kondo, Atsumasa, 2017. Sustainability of public debt in an AK model with complex tax system. In: Inequality and Finance in Macrodynamics. Edited by B. Bökemeier and A. Greiner. Cham: Springer Verlag, 159-176.

Luo, Changlin, 2014. Questioning the soft budget constraint. Annals of Economics and Finance 15, 205-215.

Morimoto, Keiichi, Takeao Hori, Noritaka Maebayashi, and Koichi Futagami, 2017. Debt policy rules in an open economy. Journal of Public Economic Theory 19, 158177 .

Reinhart, Carmen N. and Kenneth S. Rogoff, 2014. This time is different: A panoramic view of eight centuries of financial crisis. Annals of Economics and Finance 15, 215286. 